\title{
Modelica-Based Modeling and Application Framework on Hybrid Electric Vehicles
}

\author{
Yuhui Liu ${ }^{1}$ Liping Chen ${ }^{1} \quad$ Yan Zhao $^{2} \quad$ Shanshan Liu $^{3}$ Fanli Zhou ${ }^{2}$ Duansen Shangguan ${ }^{1}$ \\ ${ }^{1}$ School of Mechanical Science and Engineering, Huazhong University of Science and Technology, Wuhan, China, \\ \{yuhuiliu, chenlp, Shanggds\} dhust.edu.cn \\ ${ }^{2}$ Suzhou Tongyuan Software \& Control Technology Co., Ltd. Suzhou, China, $\{$ zhaoy, zhouf 1$\}$ @tongyuan. cC \\ ${ }^{3}$ Jianghuai Automobile Co., Ltd., Hefei, China, xjs-js@jac. com.cn
}

\begin{abstract}
In order to meet low-emissions criteria outlined in Chinese regulations, which require a progressively increasing percentage of automobiles to be ultralow or zero emissions, in this paper a sort of light hybrid electric drivetrain is studied and modeled in detail using Modelica. An application framework is also designed to improve the usability and the efficiency of the models. Performance of the whole vehicle and some key components are analyzed.. Comparison between simulation results and experiment results is performed, which validates the effectiveness of the models. Based on the comparison, we conclude that, the methods presented in this paper can support a rapid design of hybrid electric vehicles and further optimization.
\end{abstract}

Keywords: hybrid electric vehicles, Modelica, MWorks, application framework, signal bus

\section{Introduction}

Hybrid electric vehicles (HEVs) have attracted a great deal of attentions due to its high efficiency and less fuel consumption, which combines the advantages of both conventional internal combustion engine (ICE) and pure electric vehicles (Liang et al, 2016; Jionas et al, 2002). HEVs can be classified into Micro hybrid system, light hybrid system, medium hybrid system and complete hybrid system depending on the degree of colloquial in the hybrid system (Liu, 2014). Light hybrid system has been widely used due to its relatively simple structure and braking energy recovery (Zhang et al, 2014).

Basically, modeling and simulation methods of HEV s can be classified into the following three types. The first type is the traditional calculation method using excel where static results are obtained and characteristics of key components are rendered. The second type is that simulation models have already been realized based on commercial software such as advisor, AVL Cruise or Matlab libraries Toolbox (Karen et al, 1999; Meradji et al, 2016), where these models are focused on general and complex predefined. The third type is Modelica, which is suitable for dynamic analysis and developing components or function modules because of its support for multi-domain unified modelling, object-oriented physical modelling, noncausal modelling, and continuous discrete mixed modeling (Xiong et al, 2016).

In this paper, the structure of light hybrid drivetrain architecture of HEVs, is firstly studied and modeled in detail using Modelica, and an application framework is designed. Subsequently, the simulation results of the performance parameters of the whole vehicle and the key parts are obtained. Finally, the results are verified by experiment results.

\section{System Descriptions}

Before modeling the HEVs drive train represented in Fig.1 some characteristics of each element composing the system need to be mentioned:

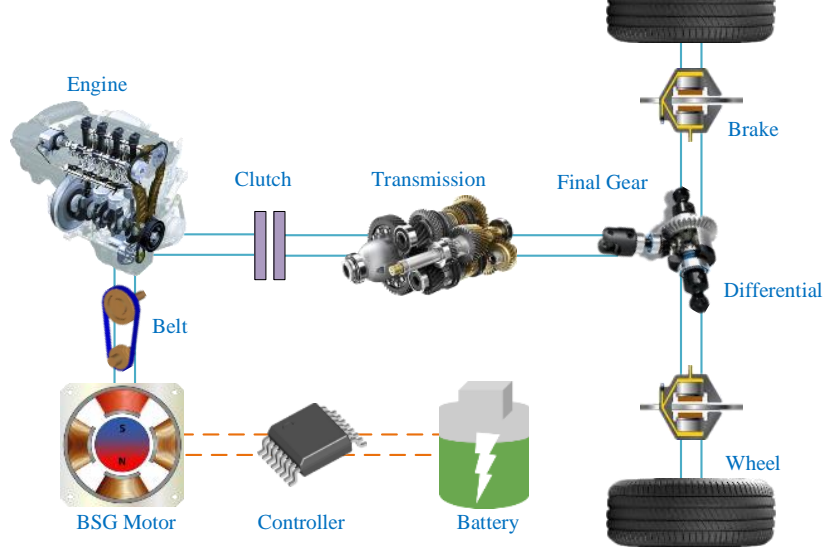

Figure 1. HEVs drive train structure.

Internal combustion engine characterized by torquespeed curve with optimal torque $T_{I C E, \text { opt }}=252 \mathrm{~N} \cdot \mathrm{m}$, The main indicator of the internal combustion engine is power output.

BSG(Belt Driven Starter Generator) motor is a belt drive integrated power generation integrated machine. Its function is to achieve fast start engine, electronic idle speed and boost when outputting positive torque, and to obtain high efficiency intelligent power generation and braking energy recovery when negative torque. 
Battery of Nickel-Metal-Hydride (NiMH) having a discharge power $\mathrm{P}_{b a t, d i s}=33700 \mathrm{~W}$ and a charge power $\mathrm{P}_{b a t, d i s}=26040 \mathrm{~W}$, is responsible for outputting or storing electrical energy, connected to BSG and DC/DC converter. The main indicators of the battery module include SOC, the state of battery charge and discharge, battery output power, and the temperature impact on the battery module.

Transmission having five forward gears are used to transmit torque and speed, which should be gear ratio and efficiency, represented in Table 1.

Table 1. Speed ratio and efficiency of transmission.

\begin{tabular}{|l|c|c|c|c|c|}
\hline Gears & $1 \mathrm{st}$ & $2 \mathrm{st}$ & $3 \mathrm{st}$ & $4 \mathrm{st}$ & $5 \mathrm{st}$ \\
\hline Gear Ratios & 3.769 & 1.862 & 1.298 & 1 & 0.765 \\
\hline Efficiency & 0.87 & 0.89 & 0.91 & 0.93 & 0.95 \\
\hline
\end{tabular}

Differential for distribute torque, is a mechanical transmission device capable of associating three shafts with the following rotation speed and torque relations:

$$
\begin{gathered}
\varphi_{\text {in }}=\frac{\varphi_{\text {out }, r}}{1+\lambda}+\frac{\lambda}{1+\lambda} \cdot \varphi_{\text {out }, l} \\
T_{\text {out }, l}=\frac{T_{\text {in }}}{1+\lambda} \\
T_{\text {out }, r}=\lambda \cdot T_{\text {out }, l}
\end{gathered}
$$

With $\lambda$ representing torque split factor, usually its value is 1 .

Clutch used to transmit and cut off engine power, have a maximum transferable torque of $350 \mathrm{~N} \cdot \mathrm{m}$.

\section{Models}

In this section, model interfaces are presentation firstly, and then introduce in detail the components and system model of HEVs developed by MWorks/Modelica.

\subsection{Interfaces}

The development is focused on standardizing the assemblies interface definitions without enforcing a standard vehicle model architecture, so that the same assembly models can be reused in different model architectures (C. Schweiger, 2005). The PowerTrain Library based on Dymola software uses expandable bus interface to facilitate the transfer of variable informations between different components, but this also leads to excessive connections and unclear connections. On the basis of PowerTrain, this paper introduces the inner/outer mechanism, which can make the variable information of each component pass through the inner component without an additional connection bus. The principle is each component contains a component signal bus pointing to the outside. The signal bus contains an expandable connector called as bus connector that sends or receives data to the bus connector within each component of the system. All components point to the same external component, allowing implicit connection of system components. The schematic diagram is shown in Fig.2.

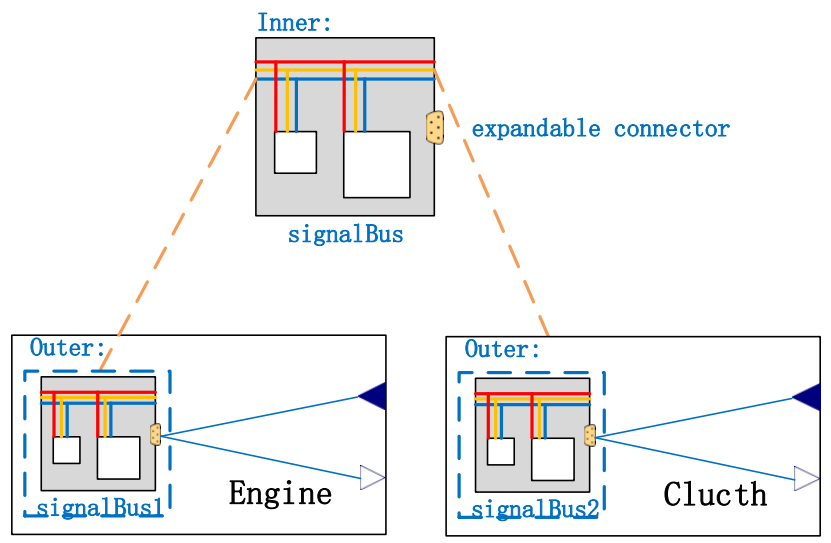

Figure 2. Bus connector design diagram.

\subsection{Component Models}

The BSG motor model consists of an internal heating model, inertia and BSG Core including both generator and motor modes. The internal heating model is used to calculate the BSG Motor temperature based on the law of conservation of energy. The BSG Core calculates the output torque and operating current of the motor, and the inertia model is used to calculate angular velocity and angular acceleration, represented in Fig.3.

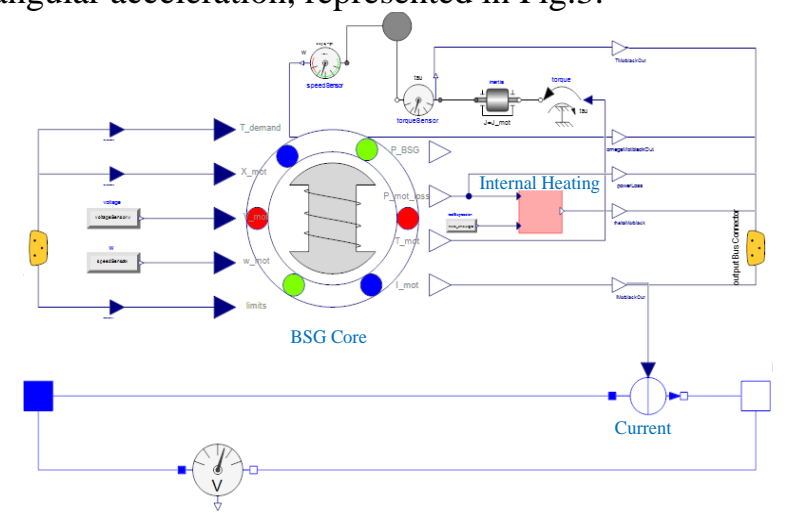

Figure 3. BSG Motor model.

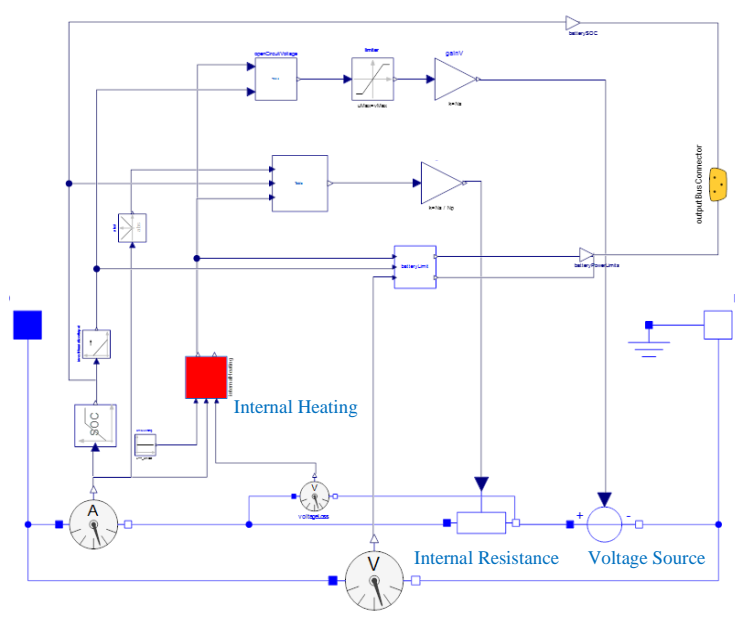

Figure 4. Battery model.

The battery model consists of a voltage source, battery internal resistance, SOC, and an internal heat module. The battery voltage is obtained by interpolation of SOC and temperature while the interpolation data 
obtained by experiments. The SOC characterizes the remaining capacity of the battery and is obtained by integration of current. The internal resistance of the battery is obtained by interpolation of temperature, current and SOC. The internal heating module is used to calculate battery temperature. (Fig. 4)

The hyboost controller model includes several function modules such as electronic idle, the brake energy recovery, power train torque demand management and the intelligent charging and discharging module (Crolla et al, 2012; Zou et al, 2015; Sanz et al, 2012). The electronic idle determines whether the engine should be dragged by the BSG motor to maintain the idle speed. The brake energy recovery is used to recover the energy by BSG power generation during braking. Power train torque demand management is used to calculate the demand torque of the driving vehicle. The function of the intelligent charging and discharging module is whether the BSG should be charged or discharged to make the engine work in an efficient area as much as possible according to factors such as the optimal operating point of the engine and the current battery capacity. The results of each hybrid control module are combined to calculate the torque and finally provide for the engine and the BSG, respectively.

The engine model provides a power output based on driving needs. Engine torque is interpolated from engine speed and throttle opening, taking into account the effects of dragging. The fuel consumption of the engine is obtained by interpolating the engine speed and the engine output torque, considering the effects of idle fuel consumption and engine temperature on fuel consumption. In this model, the engine external characteristic curve and the universal characteristic curve should be provided, represented in Fig.5.

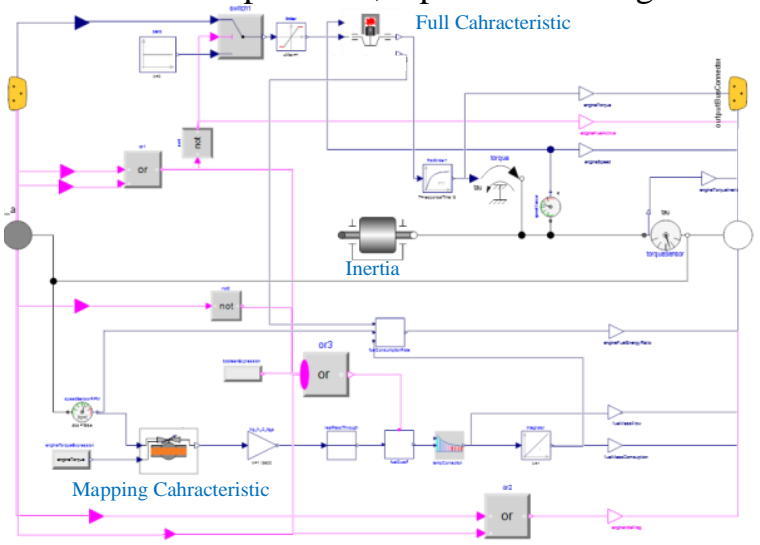

Figure 5. Engine model.

Driver model represented in Fig. 6, will determine the reference position of accelerator pedal, brake pedal and clutch pedal. Desired gear requested by comparing the vehicle speed to the desired one.

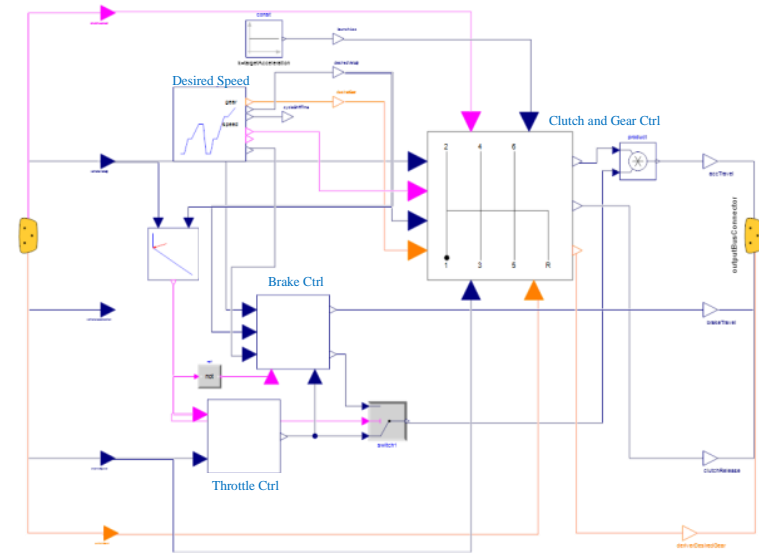

Figure 6. Driver model.

The vehicle body model is used to determine the resistant forces applied to the transmission. This is realized through a modular approach to determine different kinds of resistant forces applied to a vehicle, physical and aerodynamic drag force which provides four calculation methods. The force on the vehicle body is transmitted to the tires through the inner/outer mechanism of Modelica, represented in Fig.7.

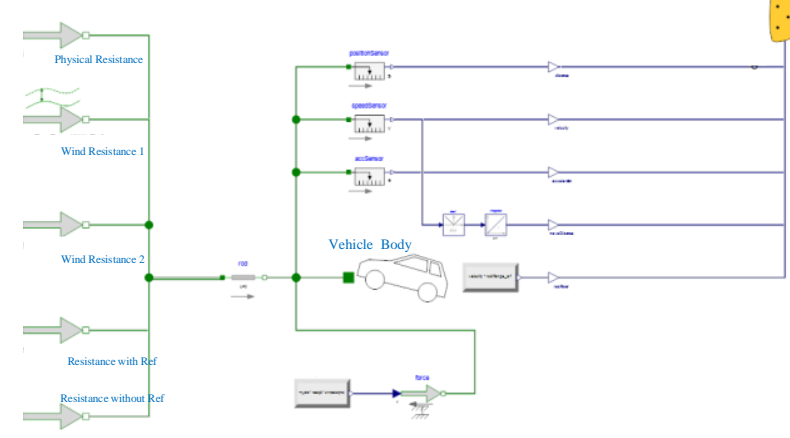

Figure 7. Vehicle body model.

The clutch, brake, final gear, transmission, and belt drive models are based on principles of the second chapter and derived from the Modelica Standard Library (version 3.2.1).

\subsection{System Models}

According to the model established in subsection 3.2 the system model of a light HEV constructed by building blocks and connecting lines, represented in Fig.8.

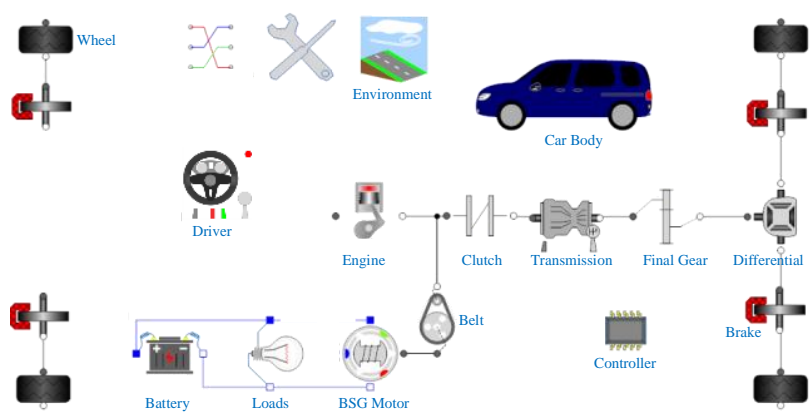

Figure 8. The light hybrid electric vehicles system model. 


\section{Framework Design}

In order to improve the usability of the software, this paper designs a general software framework for vehicle dynamics and economic simulation based on MWorks software. The workflow is shown in Fig.9, The framework can also be easily used in other domain model libraries. The software's workflow is divided into 6 steps:

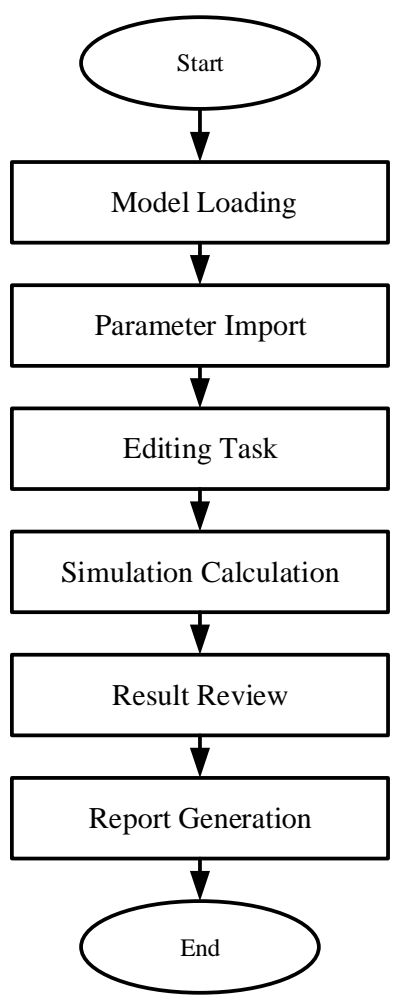

Figure 9. Flow chart of framework.

Step 1: Model loading. Select a model from the vehicle model library, for example, a manual transmission vehicle model or a Hyboost-equipped vehicle model, as shown in Fig.10;

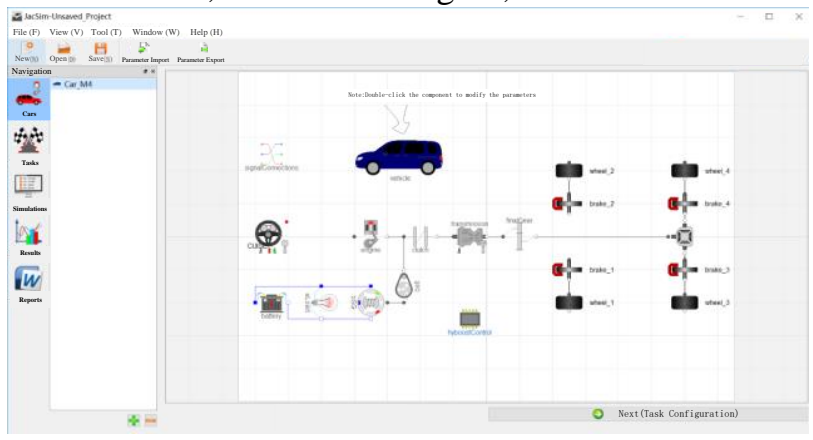

Figure 10. Model Loading.

Step 2: Parameter import. It can be set by using the parameter dialog box or importing the whole vehicle or component parameters from Excel;

Step 3: Editing task. Select tasks that need to be calculated, such as $0-100 \mathrm{~km} / \mathrm{h}$ acceleration experiment, or NEDC experiment, and then set experimental parameters, such as shift speed, as shown in Fig.11;

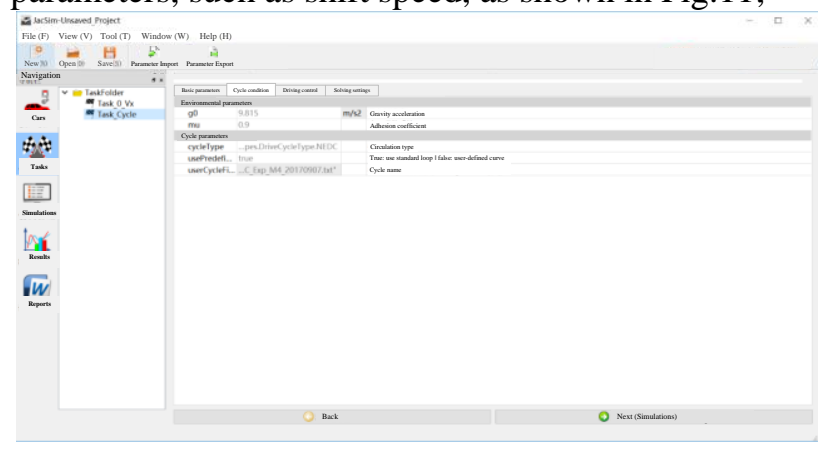

Figure 11. Editing Task.

Step 4: Simulation calculation. Three simulation methods are provided with single simulation, matrix simulation and composite simulation. Single simulation refers to the simulation of all active experimental tasks defined in the above steps. Matrix simulation means that some adjustment parameters in the model can be selected to be added to the matrix list, and then all parameters and their optional values are arranged, and then simulation is performed to all tasks for simulation. Composite simulation refers to adding components in the model to the composite simulation list, setting different batches of simulation parameters for the component, and then arranging and combining for simulation.

Step 5: Result review. The simulation results are displayed through the general and special curve windows, and the general curves are the MWorks simulation result curves, and the special curves are preconfigured curves using the xml method, such as the engine universal characteristic map.

Step 6: Report generation. The result report is automatically generated according to the configured Word template.

\section{Results and Discussion}

In this part, Modeling parameters is firstly explained based on the light hybrid vehicle (M4) of JAC, and then analyze the main performance indicators of the whole vehicle and parts on the acceleration condition from 0 to $100 \mathrm{~km} / \mathrm{h}$ and the NEDC condition. Finally, the simulation results are compared with the experiment results. Modeling parameters are shown in Table 2.

Table 2. Parameter of HEVs system model.

\begin{tabular}{|c|c|c|c|}
\hline \multicolumn{2}{|c|}{ Engine Specifications } & \multicolumn{2}{|c|}{ Final Specifications } \\
\hline Idle speed & $700 \mathrm{rpm}$ & Speed ratio & 3.273 \\
\hline $\begin{array}{c}\text { Maximum } \\
\text { speed }\end{array}$ & $\begin{array}{l}6000 \\
\mathrm{rpm}\end{array}$ & \multicolumn{2}{|c|}{ Wheel Specifications } \\
\hline $\begin{array}{c}\text { Idle fuel } \\
\text { consumption }\end{array}$ & $1.2 \mathrm{~L} / \mathrm{h}$ & $\begin{array}{c}\text { Rolling } \\
\text { radius }\end{array}$ & $0.333 \mathrm{~m}$ \\
\hline Fuel density & $0.75 \mathrm{~g} / \mathrm{m}^{3}$ & $\begin{array}{l}\text { Moment of } \\
\text { inertia }\end{array}$ & $\begin{array}{c}1.5 \\
\text { kg.m }{ }^{2}\end{array}$ \\
\hline Response & $2 \mathrm{~s}$ & Adhesion & 0.95 \\
\hline
\end{tabular}




\begin{tabular}{|c|c|c|c|}
\hline time & & coefficient & \\
\hline $\begin{array}{l}\text { Heating } \\
\text { Value }\end{array}$ & $\begin{array}{c}400000 \\
0 \mathrm{~J} / \mathrm{kg}\end{array}$ & \multicolumn{2}{|c|}{ Cluth Specifications } \\
\hline \multicolumn{2}{|c|}{ Vehicle Specifications } & $\begin{array}{l}\text { Maximum } \\
\text { Torque }\end{array}$ & 350 N.m \\
\hline Curb Weight & $2082 \mathrm{~kg}$ & Input Inertia & $\begin{array}{l}0.0315 \\
\mathrm{~kg} \cdot \mathrm{m}^{2}\end{array}$ \\
\hline Wheelbase & $2.7 \mathrm{~m}$ & $\begin{array}{l}\text { Output } \\
\text { Inertia }\end{array}$ & $\begin{array}{l}0.0047 \\
\mathrm{~kg} \cdot \mathrm{m}^{2}\end{array}$ \\
\hline \multicolumn{2}{|c|}{ Battery Specifications } & \multicolumn{2}{|c|}{ BSG Secifications } \\
\hline $\begin{array}{c}\text { Rated } \\
\text { capacity }\end{array}$ & $8 \mathrm{Ah}$ & $\begin{array}{l}\text { Motor } \\
\text { Inertia }\end{array}$ & $\begin{array}{l}0.005 \\
\text { kg.m } \mathrm{m}^{2}\end{array}$ \\
\hline $\begin{array}{c}\text { number of } \\
\text { cells }\end{array}$ & 15 & $\begin{array}{l}\text { Maximum } \\
\text { Speed }\end{array}$ & $\begin{array}{c}6000 \\
\text { rpm }\end{array}$ \\
\hline
\end{tabular}

\subsection{The acceleration condition from 0 to 100 $\mathrm{km} / \mathrm{h}$}

The velocities of the simulation and the experiment are shown in Fig.12. It can be seen that simulation velocity tracks that of the experimental result well. The acceleration time from 0 to $100 \mathrm{~km} / \mathrm{h}$ is $16.2 \mathrm{~s}$.

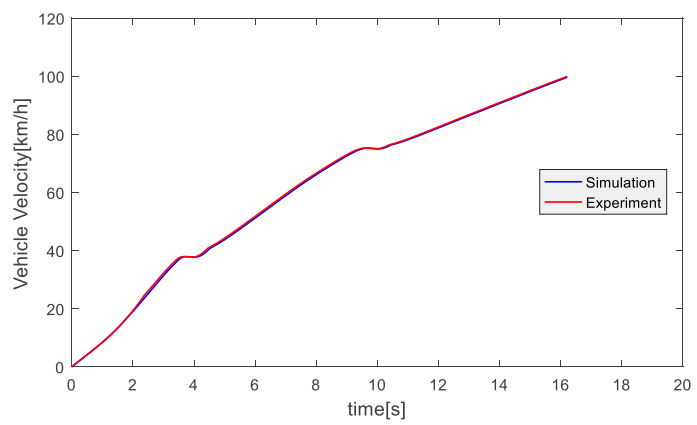

Figure 12. Results for velocities of the simulation and the experiment under condition of acceleration from $0-100$ $\mathrm{km} / \mathrm{h}$.

Fig.13 and Fig.14 show variations of engine speed and engine torque respectively where simulation results are basically consistent with the experiment results. In Fig. 10, it is difficult to keep speed of model consistent with the actual engine speed in the starting phase because the throttle and the clutch need to be cooperated by controller, and in fact it is difficult to predict the driver's operation for the driver model.

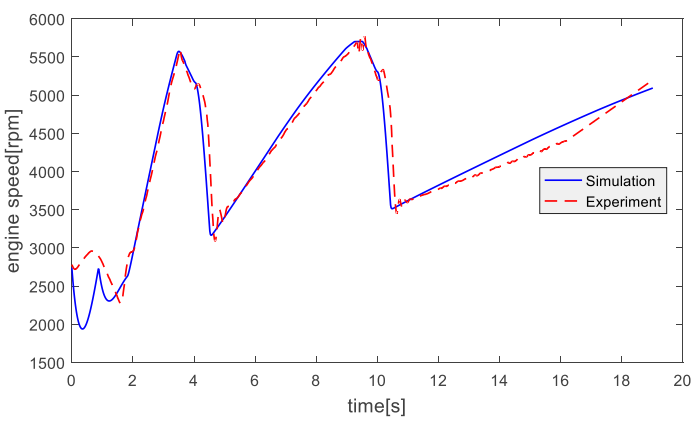

Figure 13. Results for engine speed of simulation and Experiment under condition of accelerated from 0-100 $\mathrm{km} / \mathrm{h}$.

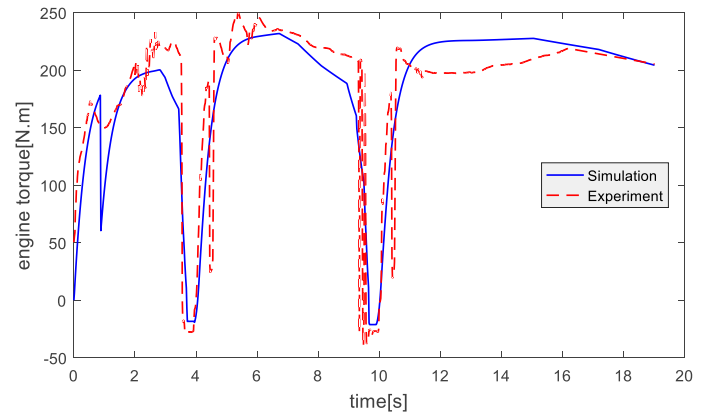

Figure 14. Results for engine torque of simulation and experiment under condition of accelerated from 0-100 $\mathrm{km} / \mathrm{h}$.

\subsection{The NEDC condition}

The vehicle velocities of the simulation and the experiment are shown in Fig.15. It can be seen that simulation velocities tracks that of the experiment well.

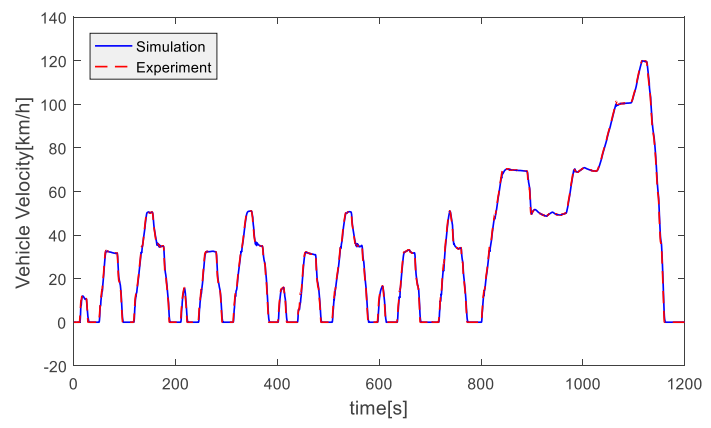

Figure 15. Results for vehicle velocity of simulation and Experiment under NEDC condition.

Fig.16 and Fig. 17 show variations of engine speed and engine torque respectively where simulation results are basically consistent with the experiment results. The reason for having different results during the parking stages is that the simulation models consider the control strategy when the vehicle is idling, the fuel supply is cut off. For real vehicle experiment, while the engine is still running leading that energy is consumed due to friction during the experiment.

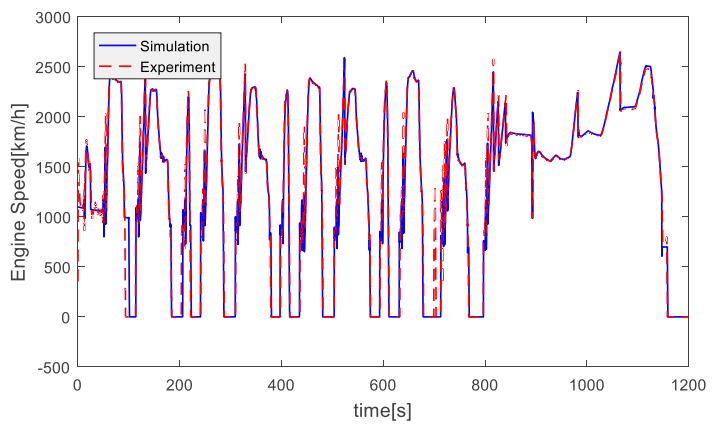

Figure 16. Results for engine speed of simulation and Experiment under NEDC condition. 


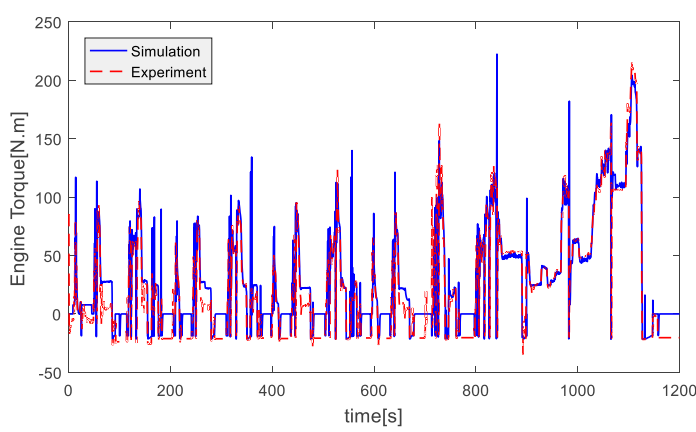

Figure 17. Results for engine torque of simulation and Experiment under NEDC condition.

Finally, Fig.18 and Fig.19 show variations of SOC and fuel consumption over the defined time period. The SOC is set as $56 \%$ initially, and the value becomes $56 \%$ at last. During the whole process of SOC is in a range from $45 \%$ to $75 \%$, which is beneficial to battery health. The fuel consumption is 0.95 gasoline. Since the last battery's charge is equal to the initial charge, the fuel consumption per hundred kilometers is approximate $9.64 \mathrm{~L} /(100 \mathrm{~km})$.

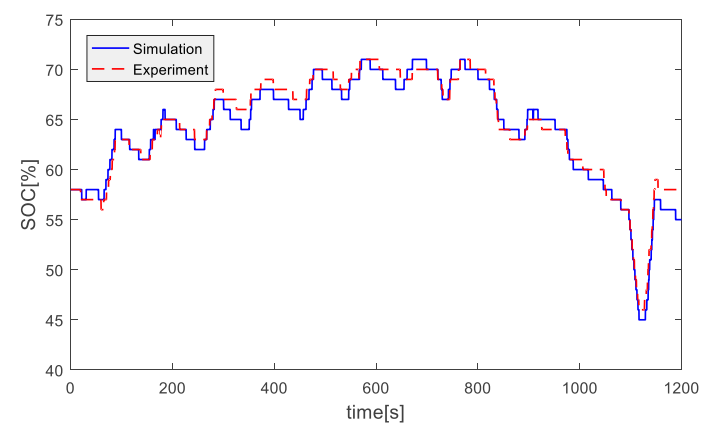

Figure 18. Results for battery SOC of simulation and Experiment under NEDC condition.

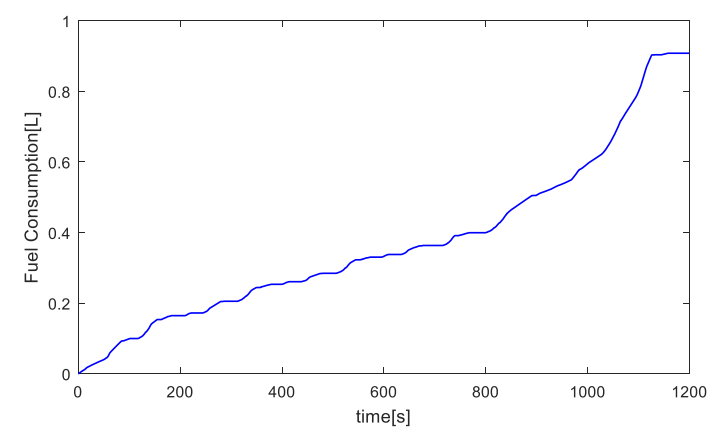

Figure 19. Results for fuel consumption of simulation and Experiment under NEDC condition.

\section{Conclusions}

In this paper a system model of a kind of light HEVs is developed, and an application framework is designed to simplify the simulation process. By using this application framework, the performance of the whole vehicle and components has been analyzed, and finally compared with the experimental results. The conclusions are as follows:

1) The application framework proposed can improve the usability of the models and the simulation efficiency.

2) The simulation results are basically consistent with the experimental results, which shows the effectiveness of the Modelica based multiphysical modeling method.

3) Through the analysis of the performance of the whole vehicle and key components such as BSG, battery, engine and vehicle body, it helps the whole vehicle matching optimization and the rapid design and verification of the system.

\section{References}

C. Schweiger, M. Dempsey, And M. Otter, The PowerTrain Library: New Concepts and New Fields of Application, in Proceedings of the 4th International Modelica Conference, Hamburg-Harburg, March 2005, The Modelica Association and Hamburg University of Technology, pp. 457-466.

D. Crolla, D. Cao. The impact of hybrid and electric powertrains on vehicle dynamics, control systems and energy regeneration. Veh. Syst. Dyn.20:95-109, 2012.

Jionas H. Modeling of hybrid electric vehicles in Modelica for virtual prototyping. 2nd International Modelica Conference, Proceedings, 2002, pp.247-256.

Karen L, Mehrdad Ehsani, Preyas Kamath. A Matlab-Based Modeling and Simulation Package for Electric and Hybrid Electric Vehicle Design. IEEE Transations on Vehicular Technology, 48 (6):1770-1778, 1999.

Liang L, Xiangyu W, Jian S. Fuel Consumption Optimization for Smart Hybrid Electric Vehicle during a Car-following Process. Mechanical Systems and Signal Processing, 87:1729, 2017. doi.org/10.1016/j.ymssp.2016.03.002.

Liu W. Introduction to hybrid vehicle system modeling and control. China Machine Press, China, 2014.pp.25-28.

M Meradji, C Cecati, G Wang, D Xu. Dynamic modeling and optimal control for hybrid electric vehicle drivetrain. IEEE International Conference on Industrial Technology, 14241429, 2016.doi: 10.1109/ICIT.2016.7474967.

Sanz V, Urquia A, Cellier, Francois E. Modeling of hybrid control systems using the DEVSLib Modelica library. Control Engineering Practice, (1):24-34, 2012.

Xiong H Y. Zhan S, Yu L M, Zhou Y S. Modelica-based Modeling and Simulation of Electric Vehicle Brake System and Parameter Optimization. Basic Research, 2:33-37, 2016.

Zhang S J, Wu Y. Hu J N, Huang R K. Zhou Y, Bao X F. Can Euro $\mathrm{V}$ heavy-duty diesel engines, diesel hybrid and alternative fuel technologies mitigate NOX emissions? New evidence from on-road tests of buses in China. Applied Energy, 132:118-126, 2014. doi.org/10.1016/j.apenergy.2014.07.008.

Zou. Y, X. Hu. M S Li. Combined state of health estimation over lithium-ion battery cell cycle lifespan for electric vehicles. Power Source, 273:793-803, 2015. 